\title{
Assessment of physicochemical characteristics and health risk of drinking water
}

\begin{abstract}
This study investigates the physical and chemical properties of bottled water and tap water at a university campus in Pahang, Malaysia. A total of seven bottled water brands, consisting of natural mineral (NM) and packaged drinking (PD) types, were first randomly selected. Three source locations of tap water were also examined. All water samples were analysed for their physicochemical characteristics, including $\mathrm{pH}$, electrical conductivity (EC), temperature (using a YSI multi-parameter), turbidity (using a turbidity meter) and selected trace metals, along with copper $(\mathrm{Cu})$ and zinc $(\mathrm{Zn})$ using graphite furnace atomic absorption spectroscopy (GFAAS). Results were then examined against World Health Organization (WHO) and Malaysian Ministry of Health $(\mathrm{MMOH})$ guidelines for drinking water. Health risks associated with trace metal were estimated using the risk assessment model. Turbidity values for tap water (2.85-4.94 NTU) were slightly higher than bottled water (0.77-1.03 NTU). A low turbidity value (0.77-0.93 NTU) suggests the presence of effective water treatment processes for NM bottled water. A low concentration of EC $(0.003-0.010 \mathrm{mS} / \mathrm{cm})$ indicates demineralization of PD bottled water. Overall quality of the bottled water and tap water was in compliance with guidelines recommended by $\mathrm{WHO}$ and $\mathrm{MMOH}$, posing a minimum health risk and remaining safe for consumption.
\end{abstract}

Keyword: Bottled water; Tap water; Trace metals; University population; Water quality 